\title{
A historiografia das produções em periódicos de Sadao Omote
}

\author{
Historiography of production in periodicals by Sadao Omote
}

\author{
Gustavo Martins PICCOLO ${ }^{1}$ \\ Saulo Fantato MOSCARDINI² \\ Vanderlei Balbino da COSTA ${ }^{3}$
}

RESUM O: buscamos através destetexto materializar o percurso histórico trilhado pel os artigos em periódicos de Sadao Omote ao longo de suas três décadas de produção acadêmico - científica. Para tanto, recorremos ao currículo Lattes do referido autor elistamos todos seus artigos (41) incorporados na referida plataforma. A pós este breve caminho exploratório, realizamos uma árida busca pela totalidade destes textos, apenas consubstanciada com a ajuda do próprio autor, o qual nos disponibilizou os textos faltantes. Feito isto, lemos minuciosamentecada artigo três vezes, extraindo deles os principais conceitos referentes à Educação Especial como campo de conhecimento. A intersecção destes elementos corporifica-sena presenteanálise, dividida em três partes, a saber: a) conceitos basilares trabal hados por Omote no campo da Educação Especial; b) idéias e apontamentos sobre o fenômeno da inclusão, dirigindo especial ênfase aos aspectos relacionados ao ambiente escolar, e; c) principais referências e temas retratados pelo referido autor; cuja concretude objetiva destacar criticamenteos principais apontamentos deSadao Omotereferenteà Educação Especial, nosso campo deestudo, epossíveis caminhos dialéticos à edificação de um sistema educacional queseja radical na qual idade deensino por eleministrada.

PALAVRAS-CHAVE: historiografia; educação especial; inclusão social.

ABSTRACT: in this text we attempted to track the historical course in the production of articles by Sadao Omote over the three decades of his academic production. We referred to his Vitae registered on the Lattes platform, where he listed all of his published articles (41). After this exploratory overview, we performed a search that enabled us to find all of his texts, which we were able to achieve with the author's help, as he provided us with themissing texts. Thenext stage required us to car efully read each articlethreetimes, extracting the main concepts related to Special Education as a field of knowledge. The intersection of these elements constitutes the basis of this analysis, divided into three parts, namely: a) basic concepts Omote worked on in the field of Special Education; b) ideas and notes on the inclusion paradigm, with special attention given to aspects relating to the school environment, and; c) main references and themes discussed by the author. Our objective was to critical ly highlight themain issues Sadao Omotehas worked on in thefield of Special Education, with possibilities for a dial ectical construction of an educational system that stands for quality in teaching, as he has advocated.

KEYWORDS: Historiography; Special Education; Social Inclusion.

\footnotetext{
${ }^{1}$ Doutorando em Educação Especial emestre em Educação pela UFSCar - gupiccolo@yahoo.com.br

${ }_{2}^{2}$ Mestrando em Educação Escolar pela Unesp-A raraquara. s_moscardini@yahoo.com.br.

${ }^{3}$ Doutorando em Educação Especial emestre em Educação pela UFSCar. vanderleibal bino@gmail.com.
} 


\section{INTRODUÇÃO}

Uma revisão de literatura podeabranger uma gama de elementos quevão desde idéias, conceitos, concepções, épocas históricas e, até a vida propriamente dita de quem se quer abordar. $O$ presente trabal ho intenta compilar todos estes fatores anteriormente citados acerca das produções em periódicos de Sadao Omote, importante pensador do campo da Educação Especial e cuja voz analítica se faz presente com certa constância na Revista Brasileira de Educação Especial .

Almejamos com este texto materializar um panorama geral da produção em periódicos de Sadao Omote, facilitando, porventura, a compreensão de suas idéias e métodos, além de trazer à baila as principais referências de seu corpo analítico eepistemológico.

Para tanto, recorremos ao currícul o Lattes do referido autor elistamos todos seus artigos (41) incorporados na referida plataforma atéo dia 08/ 07/ 2009. A pós estebrevecaminho exploratório, realizamos uma árida busca pela total idade destes textos, apenas consubstanciada com a ajuda do próprio autor, o qual nos disponibilizou os textos fal tantes. Feito isto, lemos minuciosamente cada artigo três vezes em sua respectiva ordem cronológica, extraindo deles os principais conceitos referentes à Educação Especial e as bases teóricas mais utilizadas. Em vista disso eapós o escrutíni o dos textos, dividimos o presenteartigo em três partes, a saber: a) conceitos basilares trabalhados por Omote no campo da Educação Especial; b) idéias eapontamentos sobre o fenômeno da inclusão, dirigindo especial ênfase aos aspectos relacionados ao ambienteescolar, e; c) principais referências e temas destacados pel o referido autor.

\section{Desenvolvimento}

a) Conceitos basilares trabal hados por O mote no campo da Educação Especial

Certamente a idéia que mais eco ressoa dos escritos de Omote deriva de sua concepção social da deficiência, cujo princípio ontológico apenas pode ser compreendido em sua total idade posteriormentea um estudo analítico do próprio ser humano. Para Omote (1993a, 1996a, 2006a) inexiste qual quer possi bilidade de apreensão gnosiológica do ser humano desconsi derando o caráter construtivo de suas diferenças. Estas diferenças se edificam tanto ao nível biológico da variabilidade intraespécies, como também da variabilidade interespécies, sendo as primeiras mais salientes que as segundas, pelo menos de um ponto de vista fenotípico e genotípico. Todo e qualquer animal possui seu próprio patrimônio genético que estabelece os limites de sua intervenção em rel ação à natureza.

Com base neste patrimônio genético, cada representante de determinada espécie se desenvolvea partir das relações que mantém com seu ambiente externo, as quais são assimiladas de distintas maneiras por cada ser vivo em particular, logo, mesmo os indivíduos pertencentes à mesma espécie guardam entre si 
profundas diferenças, sendo que, nas palavras deOmote(2006a, p.252), “[...] quanto mais alta é a posição ocupada por uma espécie na escala filogenética de desenvolvimento, tanto mais podem ampliar-se as possibilidades de variabilidade intra-específica".

Seguindo esta lógica indutiva, e um tanto quanto dedutiva, fica nítido em nossas retinas que nos seres humanos as diferenças se apresentam maximizadas, seja em termos quantitativos ou qual itativos, em rel ação a qual quer outro ser vivo consi derado em especial. Não bastasse isso, no caso humano, além das diferenças biológicas sobejamente conhecidas, outras são edificadas quando nossa linha de desenvol vimento enfatiza os condicionantes sociocul turais sobre os biológicos.

Desdeentão, não apenas nos adaptamos a natureza, posto termos adquirido a faculdade de explorá-la tel eologicamente, imprimindo nossa vontade sobre a conformação natural. Neste contexto, o homem passa a ser tanto produto como produtor da natureza, esuas diferenças, ao invés detril harem uma rota normativa, se complexificam na dialética relação entre o natural e o cultural, por isso, para Omote (2006a, p.253) "o homem é natural mente cultural e cultural mente biológico."

Baseado neste raciocínio, Omote (2006a) destaca que as diferenças se distribuem de maneira complexa no homem, pois além daquelas existentes no plano intraespecífico das espécies, é impossível relegar a segundo plano as diferenças relacionadas a raça, sexo, idade, cultura, classe social, religião, nível de escolaridadee, inclusive as condições geográficas do ambienteimediato.

A imensa maioria destas diferenças acaba por ser interpretada dentro dos padrões denormalidadeestabelecidos pela sociedade da qual faz parte. Todavia, al gumas diferenças, em situações específicas, recebem significados de descrédito e desvantagem social, não podendo mais ser interpretadas como variantes da norma, posto engendradas por realidades sociais altamente desvantajosas e/ ou outras de condições constitucionais como anomalias genéticas, patologias congênitas e adquiridas, traumatismos e enfermidades, etc. "[...] É a esse tipo de diferenças que nos referimos quan do falamos em deficiências." (OMOTE, 1993b, p.148).

A utilização do termo deficiência não deve, deacordo com Omote(2004b), ser confundida com a etimologia empregada para assinalar um distanciamento matemático em relação a um val or considerado normal ou médio, pois, em sentido estatístico, o gênio é tão ou mais desviante que o deficiente mental. O desvio materializado pela deficiência carrega de forma implícita uma situação de desvantagem e de prejuízo no que tange a realização de uma dada tarefa.

Para Omote (1993a, p.3), éevidenteque existeuma expressiva diferença no comportamento ou no organismo da pessoa identificada como deficiente, porém, essa diferença pode ser tanto a causa como a conseqüência do "processo de identificação, reconhecimento etratamento daquela pessoa como deficiente." N esta lógica conceitual, a referida diferença expressiva só adquire sentido de deficiência pelo fato de a sociedade val orizar determinada qualidade que nela está prejudicada, pois nenhuma diferença é vantajosa ou desvantajosa em si mesma, mas, apenas 
dentro de um contexto arquitetado pela própria estruturação sociocultural no qual estamos circunscritos.

Devido a estes fatores, de acordo com Omote (1996b), mais do que as diferenças biológicas, desde que estas não sejam negadas, são as distintas formas de apropriação e fruição sociocultural as responsáveis pela maximização da extensão das diferenças envol vendo os seres humanos. N esteverdadeiro universo ontológico, al gumas diferenças, ao contrário do que postulam teorias pós-modernas, multiculturais ou adeptas do princípio da inclusão "radical", não produzem quaisquer vantagens sociais, culturais ou funcionais, seja para seus portadores ou para aqueles que mantêm contatos dialógicos com eles, pois são diferenças incapacitantes. Essas diferenças limitam acentuadamente a prática de diversas atividades cotidianas, não sendo, para Omote (2006a, p.255), variações do padrão denormalidade, já que:

Ser diferente pela posse dessas condições não pode ser tratado como normal, sob pena de não se combaterem os determinantes dessas condições. Ainda que (ou justamente porque) a presença de inúmeras patologias incapacitantes faça parte da vida normal de uma col etividade, todos os esforços devem ser envidados para reduzir a sua ocorrência ou, na sua impossibilidade, minimizar os seus efeitos del etérios.

Com base nestes pressupostos, Omote (1996f) enfatiza que nem todas as diferenças presentes na retórica da inclusão (pois se trata mais de um discurso do quedeuma prática) são necessariamente benéficas a todosos indivíduos envolvidos em um contexto histórico determinado, já queal gumas delas limitam sobremaneira qual quer possibilidade de contato edesenvolvimento dialógico. Todavia, estas se configuram como uma parcela ínfima das diferenças que acarretam cuidados segregados, mas não segregativos, em rel ação à forma como éestruturado o meio social e a audiência dele resultante. Destarte, no mais das vezes, as deficiências, apesar dos obstácul os e possíveis impedimentos, não inviabilizam a participação das pessoas que as apresentem na produção e reprodução cultural da própria humanidade em questão, mesmo porque, para Omote (1986, 1988, 1990a, 1991a, 1995a, 1996b, 2006a), a mai oria delas éconstruída socialmente.

Não existe deficiência por si só como característica ou qual idadeendógenoorgânica referente à determinada pessoa. Omote (1997, 1990a) ressalta que a deficiência apenas sematerializa como tal mediantecritérios adotados socialmente, critérios estes estruturados a partir do próprio meio social, das exigências estabelecidas pelas atividades cotidianas e pela forma com queos outros (audiência) interpretam e se relacionam com o referido desvio. Logo, os discursos sobre as deficiências não traduzem necessariamente suas características peculiares, mas, sim, interpretações dessas características, coerentemente, a deficiência trata-se de uma questão antes política, quemédica, psicológica ou educacional. 
Aqui, a definição de deficiência perde seu caráter universal e passa a ser conceituada de forma contingencial, na medida em que alguém só é tido por deficiente em determinado contexto temporal, espacial e atitudinal (OMOTE, 1996a). Isto posto, nas pal avras de Omote (1994a, p.69):

[...] A deficiência e a não-deficiência fazem parte do mesmo quadro; fazem parte do mesmo tecido-padrão. As pessoas deficientes, mesmo que sejam portadoras de al guma incapacidadeobjetivamente definida e constatável, não constituem exceções da normalidade, mas fazem parte integrante e indissociável da sociedade.

Convém ressaltar que com esta assertiva, Omote (1994a; 1995a) não minimiza ou descarta os efeitos produzidos pela deficiência nas possi bilidades de inserção social ena própria construção do psiquismo dos sujeitos queas possuem. Muito pelo contrário, pois a idéia do autor é exatamente a de complexificar criteriosamente a constituição da deficiência, cujo conceito necessita levar em conta uma gama de fenômenos, tais como os de natureza anatomofisiológicas, somatopsicológicas e psicossociais, resultantes da relação trifásica entresujeitos/ meio social/ audiência.

Isto por que, enquanto para alguns o redirecionamento do entendimento do concei to de deficiência não produz quaisquer transformações na vida cotidiana das pessoas em situação de deficiência, para Omote(2003), novos conceitos podem resultar em novas perspectivas de investigação científica e engendrar debates acadêmicos inéditos no seio da sociedade, além é claro de possi bilitar uma gama de serviços mais democráticos e fraternos que os anteriormente propostos ou estabel ecidos. Uma amostra da veracidade detal apontamento pode ser percebida na transformação do tratamento destinado aos deficientes a partir do paradigma da inclusão, cujo foco está centrado em uma concepção social da deficiência.

Somente posteriormentea esteacontecimento, o campo deestudo sobreas deficiências passa a ser norteado por outras correntes teóricas que não aquelas oriundas das ciências naturais, possibilitando-nos a visualização da deficiência não apenas como uma característica pertencenteao indivíduo, mas, sim, como um complexo constituído pel o sujeito, meio social eaudiência.

Como consequência lógica, os serviços que atendem as pessoas com deficiência também sofreram al terações significativas, uma vez queforam obrigados a se transformar com vistas a fornecerem as máximas possibilidades de desenvolvimento a estes indivíduos. A lém disso, novos locais, antes restritos, são abertos às pessoas com deficiências posteriormente ao acirrado debate promovido pelos postulados da inclusão, dentre os quais, podem ser citados o mercado de trabal ho, as escolas esal as de aula regulares, os espaços esportivos, etc.

Destarte, não podemos entender a reflexão analítica sobrea construção social da deficiência como a socialização organicista desse fenômeno. Entender a 
deficiência como social não pode implicar na subestimação dos componentes biológicos presentes na arquitetura da deficiência. Talvez, embora não dito, os autores que interpretam a deficiência como um fenômeno socialmente construído, tais como Omote (1986, 1988, 1990, 1991, 1995a, 1996b, 2004, 2006) e Goffman (1980), entreoutros, objetivaram materializar a difundida tese de Lênin sobrea curvatura da vara (1979), que estabel ecequeem determinadas situações históricas al tamente alienantes (eacreditamos quea visual ização da deficiência na soci edade seja uma delas), não basta apenas recolocar as relações componentes de determinado fenômeno sob parâmetros equitativos.

Às vezes, de acordo com Lênin (1979), é importante analiticamente extrapolar o fenômeno para o outro lado, curvar a vara, intuindo que após esse movimento elíptico possamos finalmente compreender sua gênese e desenvolvimento. Logo, a interpretação da deficiência como um fenômeno socialmente construído deve ser interpretada não no sentido de obnubilar os componentes biológicos de sua constituição, mas, sim, como uma tentativa dere/ configurar uma relação historicamente enviesada pelo prisma biologicista e cartesiano.

Voltando ao escopo analítico do trabalho, destacamos ser em função do caráter intrincado assumido pela deficiência na sociedade que comportamentos idênticos podem ser cotejados por interpretações essencialmente díspares em contextos históricos desiguais. Logo, nem todas as características conceituadas como deficiências em certo contexto se estendem para outras realidades, posto que as mesmas não representem qualquer significado de desvantagem social. Contudo, estas colocações não mi nimizam o combate as condições que direcionam as pessoas a funcionarem de forma precária, como as profundas desigualdades sociais e a necessidade de prevenção deal gumas moléstias, al iás, tal combatetorna-se ainda mais acirrado quando as deficiências são encaradas como constructos sociais, pois como ressalta Omote (2006a, p.266), “uma sólida proposta de inclusão, em todas as instâncias da vida coletiva, precisa buscar um esforço solidário entre o combate às mais variadas condições incapacitantes e o tratamento cidadão de todas as pessoas acometidas por tais con dições."

Exatamente nesse sentido, Omote(1999b), sublinha o conceito de inclusão como sendo um campo profícuo ao entendimento eao trabal ho com as múltiplas diferenças etambém com as deficiências, na medida em que redireciona o foco de atenção do indivíduo para o meio, sendo que o pano de fundo desta questão é estabelecido pela assunção dessa nova concepção de deficiência, a saber, a construção social da deficiência, a qual, sem ignorar as condições biológicas incapacitadoras, coloca a ênfase na significação imposta ao conceito de deficiência pela sociedade. 
b) I déias e apontamentos sobre o fenômeno da inclusão

Não restam dúvidas de que o imperativo de uma sociedadeem ser inclusiva justifica-se não só pela heterogeneidade em sua constituição, mas fundamental mente pela heterogênea e desigual distribuição de recursos, riquezas e possibilidades de fruição cultural aos mais diversos seres humanos (OMOTE, 2006a). Por isso, a inclusão, mais do que uma filosofia, é um imperativo ético e moral do qual não podemos nos imiscuir. Direcionando nosso foco deanálise para as questões relacionadas direta ou indiretamente ao aparato escolar, percebemos que os defensores da inclusão deal unos com deficiência na rede regular deensino justificam sua posição enfatizando os inúmeros ganhos obtidos com tal processo para todos os envolvidos nas relações de ensino-aprendizagem.

Estes benefícios iriam além daqueles advindos da aprendizagem escolar, englobando também o desenvolvimento de atitudes favoráveis para com os deficientes, propiciando a edificação de uma postura crítica às manifestações preconceituosas e discriminatórias. Logo, o conceito de inclusão carrega organicamente a necessidade de uma profícua al teração por toda a sociedade em relação à forma como ela vêe interpreta a deficiência (OMOTE, 2005a). Na esteira crítica deste processo, Omote (2006a, p.258), destaca que:

[...] M uitos portadores dessas condições (deficiências) que, no passado recente, eram escolarizados em ambientes educacionais restritivos como classes e escolas especiais, podem e devem ser educados em classes deensino comum, em conjunto com col egas não deficientes. Com diferentes graus de adaptações nos recursos de ensino, avaliações e objetivos, certamente a maior parte de crianças com deficiência visual, auditiva efísica, assim como uma parcela de deficientes mentais, outrora referidos por educáveis, eatépartedos chamados treináveis, como os portadores da síndrome deDown, podeser escolarizada em classes deensino comum.

Todavia, como todo processo dialético, a inclusão (mesmo considerando-a como um discurso) propalada pela Declaração deSalamanca, firmada em 1994, além deaspectos positivos também trouxemazel as que precisam ser debatidas demaneira urgente. Uma delas reside na substituição do termo deficiente por pessoas com necessidades especiais, cuja materialidade, além de não exercer quaisquer efeitos palpáveis sobre a prática da rotulação, ainda obnubila as especificidades que as pessoascom deficiência possuem em rel ação ao restanteda população. É nestesentido queOmote (2004b) sobreleva a importância do estigma nas sociedades atuais.

Outra consequência negativa, causada por uma interpretação radicalista (não utilizamos radical, pois etimologicamente designa aquilo que vai a raiz) e simplificada da inclusão, diz respei to à el imi nação dos serviços especializados ao tratamento das deficiências em detrimento de atendimentos, a priori, capazes de educar a todos. Assim, sob a suposta justificativa de os serviços especializados maximizarem a criação deestigmas sobre seus usuários e aumentarem sua condição 
de especial, na medida em que o encaminhamento às classes especiais se dava como um processo paral elo e sem relação com o que era realizado nas classes regulares, sugere-se, do dia para a noite, o fechamento destes atendimentos, desconsiderando-se, por conseguinte, de acordo com Omote (2004b), a extensão em que determinada condição incapacitadora limita o funcionamento de uma pessoa e denota a necessidade de recursos.

A inclusão não pode invalidar a existência de um serviço segregado necessário para sua população sob qual quer argumento democrático, todavia, deve estabel ecer parâmetros para queo envio a este serviço se dêa partir deevidências cientificamentefiáveis, permitindo o máximo desenvolvimento deseus usuários, mesmo porque, como apontam A raújo eOmote (2005b, p.245):

\begin{abstract}
A existência deatendimento em separado, parcial ou totalmente, não configura necessariamente a construção de um mundo à parte para os seus usuários. Mais ainda, graças ao atendimento de uma necessidade específica eespecial, proporcionado pela existência de serviço especializado e segregado, os seus usuários podem fazer-se presentes em diferentes cenários da vida coletiva, contribuindo para a existência efetiva da variação. O que deveser questionado é o tratamento diferenciado de deficientes, baseado na categoria à qual pertencem enos estereótipos a ela associados. A prescrição de qual quer serviço especial deveocorrer em função denecessidades específicas de cada indivíduo, mediante a correta avaliação das possibilidades de utilização de serviços comuns ou especiais. É a prescrição categorial, tão freqüente e naturalmente praticada até um passado recente, que deveser evitada.
\end{abstract}

Portanto, a criação de serviços especiais, ao invés de atravancar o processo de inclusão, significa uma importante extensão no acesso à escola por crianças com deficiência, na medida em que permitem trazer para seu interior alunos que historicamente estiveram excluídos do ambiente escolar por apresentarem determinada deficiência. Assim, seu suposto caráter segregativo deve ser criticamenterepensado, pois, nas pal avras de Omote(1999b, p.8):

[...] os recursos de Educação Especial têm sido criticados como segregativos porque têm sido utilizados como um freio para o percurso do deficiente em direção à integração. Sealunos que poderiam estar em classedeensino regular são mantidos em classes especiaise secrianças deficientes quepoderiam receber educação escolar em classes especiais da rede regular de ensino são mantidas em escolas especiais, então, de fato, esses recursos de Educação Especial cumprem a função segregativa. Entretanto, pode-se conferir-Ihes função integradora. Isso podeocorrer, se crianças deficientes confinadas em casa forem atendidas em escolas especiais, se crianças mantidas em escolas especiais e que apresentam condições de alfabetização forem encaminhadas a classes especiais da redee sealunos mantidos em dasses especiais forem encaminhados a classes comuns, na medida em que apresentem condições para isso. N aturalmente, um recurso que cumpre a função integradora precisa buscar ad equação às condições e necessidades do usuário que pretende integrar, sem que, com isso, descaracterize o serviço e seus objetivos. Deveficar claro queo caráter segregativo ou integrador depende fundamental mente do modo como o recurso é utilizado. 
Deste modo, o importante a frisar é que, independentemente do grau de comprometimento, as pessoas com deficiência devem ter acesso aos serviços de máxima qualidade possível, seja el esegregado ou não. Logo, nas palavras deOmote (2006a, p.260), "radical etotal deveser a provisão deserviços para 0 aten dimento das mais variadas necessidades de toda a população". Desta feita,

Não seria, nessa perspectiva, aceitável a possibilidade de algum deficiente não receber serviço de qualidade por considerar-se imprescindível o seu atendimento junto com outros usuários, em espaço comum, em nome da inclusão. É essa ampla variação ambiental que otimiza as condições evolucionárias capazes de dar as melhores (não necessariamente iguais) oportunidades àqueles que, se mantidos no atendimento comum destinado a todos os usuários sob a expectativa da igualdade, seriam excluídos da participação nessa história. É a inclusão praticada radical e rigorosamente (ARAÚJO; OMOTE, 2005b, p.245)

Seguind o semel hantelógica econtestand o al guns postulados colocados por defensores de um modelo de inclusão radical ista, Omote (1999b, p.10) enfatiza que nunca é demais lembrar que os benefícios da inclusão precisam ser para todos os al unos. N esta perspectiva, a colocação dealunos com el evado grau de deficiência em salas regulares sem o mínimo preparo para seu atendimento pode gerar uma desigual dadeainda maior do que do que aquel a presenciada cotidianamente, além disso, "pode prejudicar o rendimento da classe toda, acabando por nivelar por baixo 0 desempenho dos alunos deficientes e não deficientes". Extrapolando as considerações para além das pessoas com deficiência, Omote (2006a, p.260-261) destaca que:

O grande desafio da inclusão, por ora, certamente não é atender deficientes com tal grau decomprometimento, mas prover ensino de qualidade a todas as crianças ejovens que apresentam variações nas suas características lingüísticas, culturais, sociais, étnicas, de afiliações grupais e outras diferenças perversamente impostas por uma grande desigualdade social. As oportunidades de acesso precisam ser asseguradas a todas essas crianças e jovens. [...] A enormidade do desafio dessa tarefa pareceum tanto ofuscada na medida em que se destaca, no discurso da inclusão, o desafio de prover educação de qualidade a deficientes em conjunto com seus pares não deficientes, medianteas necessárias adaptações nas condições de infra-estrutura física da escola - incluindo a arquitetura do edifício escolar, o acervo de biblioteca e de laboratórios, os recursos pedagógicos, o mobiliário e outros materiais e equipamentos - bem como nos aspectos didático-pedagógicos incluindo aí as adaptações nas estratégias de ensino e atividades de aprendizagem, na avaliação e eventualmente até em alguns dos objetivos educacionais. A espetaculosidade das adaptações arquitetônicas e do uso de equipamentos, mobiliário erecursos pedagógicos édeal ta visibilidade, maior queo esforço empreendido pelo professor no uso das diferentes estratégias de ensino, em busca de atendimento às necessidades ediferenças menos evidentes de seus al unos carentes deexperiências, vivências eoportunidades essenciais para o seu desenvolvimento pleno. Com isso, a discussão atual da inclusão pode estar tirando de foco a crônica dificuldade da educação brasileira de prover ensino de qualidade a crianças e jovens provenientes de camadas pauperizadas da população. 
Coerentemente, Omote (1999b) destaca que os postulados colocados pelo princípio de inclusão não podem ser de tal monta que eliminem os problemas anteriores enfrentados pelo nosso sistema educacional, al iás, não devem sequer remover al guns profícuos apontamentos contidos nas idéias originas deintegração e normalização como se fossem uma coisa do passado, pois:

O esforço feito tanto pelo deficientequanto pelas pessoas com as quais convive, para que a pessoa deficiente consiga levar um modo de vida o mais próximo possível do de pessoas comuns, continua a ser um princípio norteador importante. Do mesmo modo, étambém importantea orientação assumida no sentido de capacitar o deficiente a atender às demandas do meio para que consiga fazer partedelede modo competente. Talvez, um grave erro cometido no passad o fossea visão enviesada que resultou em ações unilaterais nas quais o esforço feito para alcançar a integração no meio social cabia às pessoas deficientes. Talvez, os princípios que fundamentam a inclusão sejam aceitos tão prontamentee com tanto entusiasmo por tanta gente, em parte, para reparar esse grave erro do passado. Corre-se o risco, entretanto, de substituir aquele erro por um outro equívoco, na extensão em quea ênfase na necessidade dea escola buscar detodas as maneiras possíveis a adequação às necessidades de cada al uno pode levar-nos a ignorar a necessi dade de que cada indivíduo se sujeiteàs normas da coletividadee aprenda a fazer uso dos recursos disponíveis destinados às pessoas em geral, sempreque houver condições para desenvolver essas competências. (OM OTE, 2006a, p. 264-265).

Para Omote et al (2005d), outro dos equívocos contido em uma concepção radical ista de inclusão residena pressuposi ção de que não seria mai s necessária a formação especial izada de professores deEducação Especial, na medida em quea ênfase deveria estar dirigida a um processo de formação general ista. O raciocínio contid o nesta assertiva carrega implicitamente duas importantes posições sectárias defendidas pela inclusão radical ista, quais sejam: a de que o processo de formação generalista se contrapõe à formação do especialista, e, a de que o professor generalista pode atender a toda diversidade presente nas sal as de aula, inclusive aquelas derivadas de um al to grau de comprometimento funcional. Comentando sobre a suposta contradição existente entre professor generalista e especial ista, Omote (2003, p.30-31-32) destaca que:

[...] tanto os professores do ensino comum precisam especializar-se para atender aos deficientes com suas peculiaridades, em suas dasses, quanto os deEducação Especial precisam ampliar suas perspectivas, tradicional mentecentradas nessas peculiaridades. Os deficientes possuem características peculiares que precisam ser conhecidas pelos professores deensino comum. E os professores de Educação Especial não podem continuar com a sua atenção centrada nessas características, sob pena detransformar o atendimento especializad o em um meio depromoção da segregação deseus usuários. [...] A inda que possa parecer paradoxal , diante do discurso corrente da inclusão, acreditamos necessitar de tanto mais profissionais altamente especial izados em recursos, métodos etécnicas específicos quanto mais se pretende ampliar as oportunidades de acesso, participação e realização de um número crescente de deficientes, independentemente da natureza e do grau decomprometimento. 
A longa citação justifica-se pel o conteúdo e por delinear de maneira precisa a suposta contradição entre o professor generalista e o especialista. Parece até engraçado, mais constatamos que o discurso mais acalorado sobre a inclusão simplesmente despreza as possibilidades de diálogo entre profissionais com diferentes formações. Se a inclusão começa efetivamente pelo diálogo, fica claro que o caminho radical ista não aparenta se constituir como uma boa solução. Este diálogo deveser promovido não apenas entreos mais diferentes professores, alunos e comunidade escolar, mas também entre o sistema de ensino regular e especial, na medida em que estes não são serviços paral elos, mas umbilical mente ligados, ou mel hor, deveriam ser (OMOTE, 1995c).

A tessitura destes apontamentos traz à tona a necessidade premente de investigarmos mais detidamente os desdobramentos engendrados pelo fenômeno da inclusão, cujas consequências derivam-se tanto para as pessoas em situação de deficiência como para aquel as tidas por normais. Claro está que esta éuma tarefa praticamente embrionária se consi derarmos a prematuridade das discussões acerca da inclusão escolar, porém, sua col ocação analítica perfaz um bom caminho para pensarmos epistemologicamente o campo da Educação Especial como fenômeno em si e, principal mente, direcionarmos nossas ações para que as pessoas em situação de deficiência possam se apropriar eobjetivar-senas múltiplas produções culturais do gênero humano.

Esse é nosso grande desafio acadêmico e prático, por isso, a profunda importância em refletirmos sobre al guns conceitos basilares ao campo de nosso estudo, pois se é fato que as palavras e conceitos por si só não transformam a realidade, como bem pontua Marx (1996), também o éque elas exercem certo efeito transcendente na configuração das mais distintas práticas sociais, as quais podem sevaler de pressupostos mais democráti cos e fraternos (nossa expectativa), ou de el ementos competitivistas e segregacionistas, tão em voga em um sistema social historicamente classista e hierárquico. Passemos agora a destacar um panorama geral dos temas e autores trabal hados por Sadao Omote.

\section{c) Principais referências e temas destacados por 0 mote}

Realizar uma análise historiográfica da produção de qualquer autor influenteem determinada área acadêmica envolvecertamenteum mínimo trabal ho estatístico demonstrando as peculiaridades características do processo de produção intelectual do referido autor. É exatamente isto que pretendemos fazer neste momento. Comecemos pel os principais temas trabal hados por Omoteao longo de seus 41 artigos publicados em periódicos atéo mês dejulho de 2009, expressos no seguintegráfico. 


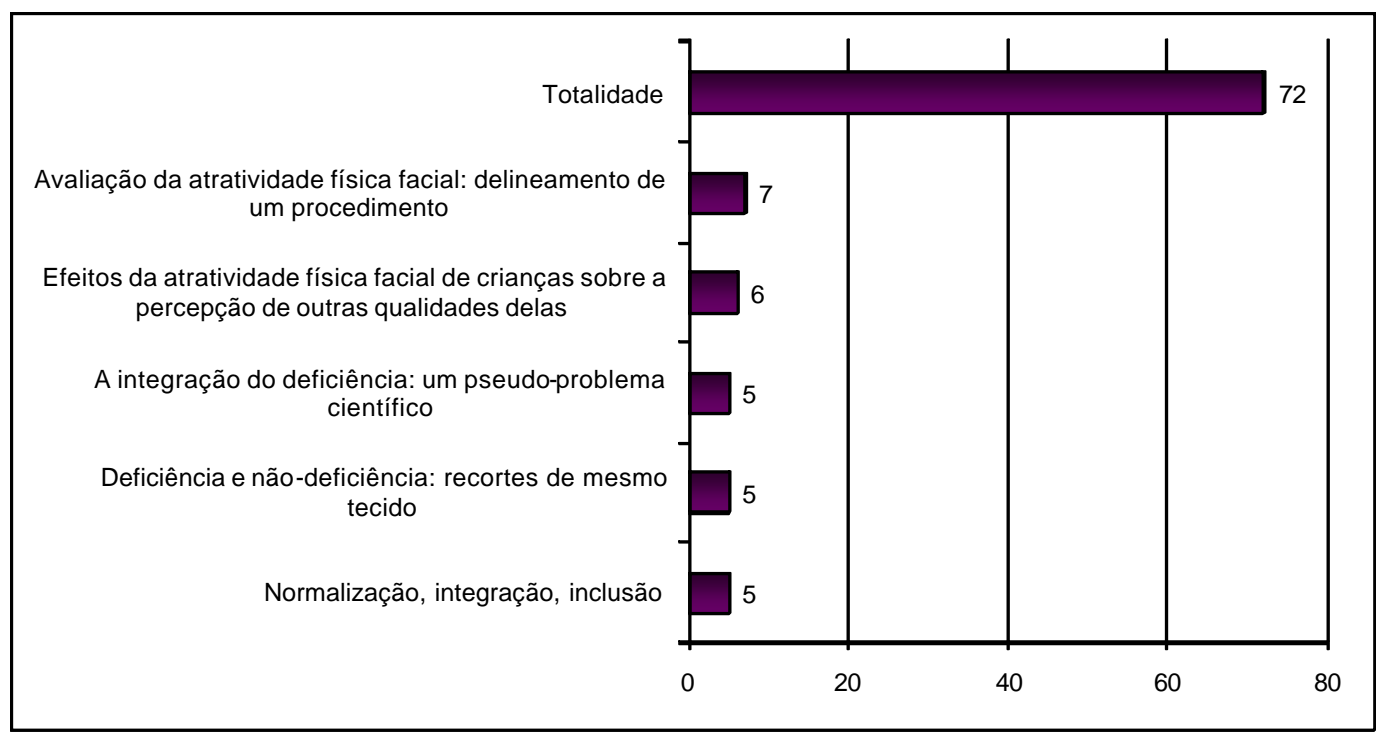

Figura 1 - Principais temas trabal hados por Omote

Direta ou indiretamente, tod os estes temas foram trabal had os estabel ecendo relações com a área de Educação Especial, até mesmo quando Omote (1990b (et al.), 1995b (et al.), 2005c, 2005e (et al.), 2005a, 2006b (et. al.)) foca suas atenções tel eol ogicamentena importância dos aspectos metodológicos na construção de uma pesquisa válida e confiável ${ }^{4}$. $\mathrm{N}$ ota-se aqui que os aspectos conceituais das deficiências e sua formatação histórica se configuram como as principais problemáticas tratadas por Omoteao longo de seus estudos, o que se justifica pelo fato de o referido autor acreditar que a conceituação das deficiências não se concretiza apenas como questão etimológica, pois sua materialização interfere significativamente na qualidade do atendimento destinado as pessoas com deficiência e no próprio pensar acadêmico sobre a Educação Especial .

\footnotetext{
${ }^{4}$ Omote demonstra uma preocupação basilar quanto ao rigor necessário para a efetivação de uma pesquisa de cunho acadêmico-científico. Neste sentido, em diversos artigos, Omote (1990b (et al.), 1995b (et al.), 2005c, 2005e (el al.), 2005a, 2006b (et. al.)) discute especificamente a questão do método e dos procedimentos metodológicos adotados, validando a utilização de dois instrumentos científicos para a mensuração de uma escala de atitudes sociais em relação à inclusão, denominados ELASI (Escala Lickert de A titudes Sociais em relação à Inclusão), dividido em suas formas A e B. A lém disso, Omote (ibid) tece importantes comentários acerca do processo de revisão por pares, das vantagens da utilização do questionário el etrônico para a realização das mais diversas pesqui sas e escrutina os critérios que devem ser adotados em uma entrevista para que esta se torne uma ferramenta fidedigna a coleta de dados.
} 
A temática da atratividadefísica/ facial também recebediversas pontuações nas obras de Omote (1983, 1991b, 1991c, 1993b, 1993c, 1999a, 2005d (et al.)), sendo constantemente relacionada com o fenômeno da produção de estereótipos e de como estes interferem na conformação das rel ações sociais estabel ecidas entre os seres humanos ${ }^{5}$. A lém destes, cabe ressal tar em Omote (1979, 1993d, 1996e, 1996c (et. al.), 1996d (et al.), 1996g (et. al), 2000a, 2004a (et. al.) o tema família e sexualidade ${ }^{6}$, assunto polêmico e de difícil resolução no contexto da Educação Especial , e, tópicos diversos queversam sobre a carrei ra profissional do deficiente ea importância da interdisci plinaridade no trabal ho visando à superação dialética da deficiência. Estes temas foram trabal hados ao longo de 30 anos deestudo, cuja distribuição éexposta no gráfico que segue.

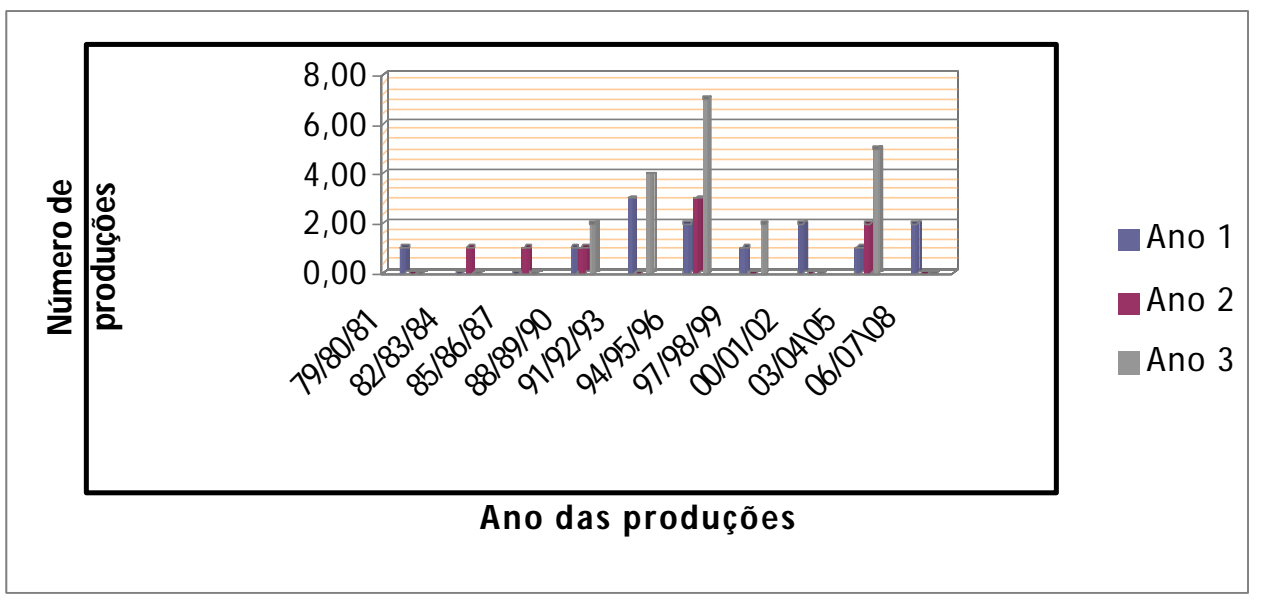

Figura 2- Temas trabal hados ao longo de 30 anos de estudo.

\footnotetext{
${ }^{5}$ Para Omote (1983, 1991b, 1991c, 1993b, 1993c, 1999a), os rostos constituem-se como o el emento determinante de nossa aparência física, por isso, quando o autor investiga epistemologicamente a questão da atratividade física, a face assume primazia em ordem de importância sobre outras áreas corpóreas. A atratividade física facial éuma importante variável que influencia a construção de nossas mais diversas relações em sociedade, tais como: formação de casais, ocupação no mercado de trabal ho, avaliação da popularidade, quantidade de amizades, avaliação da competência social eacadêmica, interação do professor com os alunos, etc. Todas essas diversas relações recebem o crivo da atratividade física, portanto, ser bel o na sociedade não se configura apenas como uma questão estética, na medida em que possibilita uma série de experiências não disponíveis, ou disponíveis negativamente, para os considerados não belos.

${ }^{6}$ Claro está que são dois assuntos distintos, porém, el es aparecem entrelaçados em diversos artigos publicados por Omote (1979, 1993d, 1996c (et al.), 1996d (et al.), 1996e 1996g (et al.), 2000a, 2004a(et al.)). Omote(1993d, 1996e) ressal ta a importância na promoção de estudos que investiguem a fundo as famílias dos deficientes, fornecendo à el as todos os suportes necessários para a compreensão da deficiência e das múltiplas possi bilidades de desenvolvimento de seus filhos Um destes apoios certamente deve se material izar acerca do assunto: "sexual idade do deficiente", pois historicamente assumiu a configuração de um tema tabu na sociedade, tabu estearquitetado de maneira binária, pois ora os deficientes são vistos como seres praticamenteassexuados, ora como uma pessoa com necessi dades sexuais insaciáveis. Estes arquétipos sobrea sexual idade das pessoas com deficiência tendem a se acentuarem devido à desinformação dos pais sobre a sexualidade de seus filhos e também desua própria sexual idade, limitando os acessos deinformação a seus filhos, cujo resultado atravanca o processo de desenvolvimento da própria pessoa em situação de deficiência.
} 
O referido gráfico nos mostra uma tímida produção de Omote em seus anos iniciais após a conclusão de seu mestrado em Psi cologia no ano de 1980 pela USP, produção essa que se acentua na década de 90 com os estudos sobre atratividade física facial, tema predominante de seus artigos nesta época, conjuntamente a sua preocupação filosófica em relação à conceituação das deficiências, cuja ênfase se solidifica notoriamente nas últimas produções do referido autor.

Desde o primeiro ano do século XXI este é o principal aspecto abordado por Omote em seus artigos, todavia, sua produção parece entrar em curva descendente no último triênio anal isado. Aliás, até mesmo quando utilizamos o corte decenal e não trienal percebemos uma queda no número de produções de Omote, pois em seu primeiro decênio (79/ 88) acadêmico, o autor produziu 4 artigos, já no segundo (89/98), sua produção cresceu exponencialmente para um total de 23 artigos, por fim, no terceiro decênio (99/08), nota-se um declínio no número de produções para 14 artigos, significativamente menor que o anterior, todavia, é importanteressaltar quequantidadenem semprequer dizer qualidade. Além dos elementos anteriormente destacados, é importante ressal tar que não estamos trabal hand o com a total idade das obras produzidas por Sadao Omote, mas apenas com suas produções em periódicos. A ssim, não computamos para estes cál cul os livros e capítul os de livros feitos ou organizados pel o referido autor e tampouco apresentações em congresso, elementos quenão podem deixar deser considerados em uma anál ise gl obal desuas produções, porém não é esteo objetivo do referido artigo. A dentrando na densidade dos textos escritos por Omote nas três décadas destacadas anteriormente, podemos perceber que em seus 41 artigos Omote menciona um total de 325 obras (citadas 1228 vezes ao longo de seus diversos parágrafos), as quais induem livros, capítul os delivros, dissertações eteses, artigos e declarações internacionais sobre educação. Os autores e obras mais citadas por Omote são encontrados na Tabela 1, a seguir:

Tabela 1 - Estatística sobre os autores mais citados por Omote.

\begin{tabular}{lcccc}
\hline Autores & $\begin{array}{c}\text { Número de } \\
\text { citações }\end{array}$ & $\begin{array}{c}\text { Obras } \\
\text { citadas }\end{array}$ & $\begin{array}{c}\text { Obras da Educação } \\
\text { Especial }\end{array}$ & $\begin{array}{c}\text { Obras da Sociologia e } \\
\text { Psicologia }\end{array}$ \\
\hline ABRAMOWICZ & 13 & 002 & 0 & 2 \\
ALMEIDA & 38 & 001 & 1 & 0 \\
BAROCAS & 31 & 006 & 2 & 3 \\
BARTEL & 28 & 007 & 4 & 3 \\
BRADLEY & 30 & 006 & 3 & 0 \\
DENARI & 25 & 001 & 1 & 2 \\
DEXTER & 27 & 008 & 6 & 2 \\
DOBZHANSKY & 41 & 001 & 0 & 0 \\
FRIEDMAN & 29 & 005 & 3 & 2 \\
GLAT & 29 & 005 & 5 & 0 \\
GOFFMAN & 48 & 002 & 0 & 0 \\
MERCER & 46 & 009 & 4 & 3 \\
PASCHOALICK & 26 & 004 & 4 & 27 \\
PIROVANO & 25 & 002 & 2 & 5 \\
SALVIA \& & 39 & 008 & 5 & 1,8 \\
ELOVITS & & & & \\
TOTAL & 475 & 067 & 40 & 6 \\
MÁXIMO & 48 & 009 & 0 & \\
MÍNIMO & 13 & 001 & 2,666666667 & \\
MÉDIA & 31,66667 & 004 & & \\
\hline
\end{tabular}


Esta tabela nos revela diversos elementos na produção em periódicos de Omote. O primeiro deles certamente reside na vasta bibliografia utilizada pelo autor, a qual mescla obras da Psicologia, Sociologia e Educação. No entrelaçar destes três campos específicos, Omote constrói sua concepção sobre deficiência, interpretando-a como um fenômeno que se arquiteta de maneira complexa, na medida em que sua constituição recebe tanto a interferência dos fatores biológicos propriamente ditos, como também dos elementos psicológicos e sociais. Assim, enganam-se os que pensam que Omote considera a deficiência apenas como fenômeno social mente construído, para ele, a deficiência éestabelecida a partir de um complexo estrutural queengl oba tanto variáveis biológicas, como as decunho social e psicológico. O gráfico seguinte(Figura 3) retrata o caráter multifatorial na construção do conceito de deficiência realizado por Omote, uma vez que permitea visualização do espaço tracejado pelas suas princi pais referências sob um prisma não hierárquico.

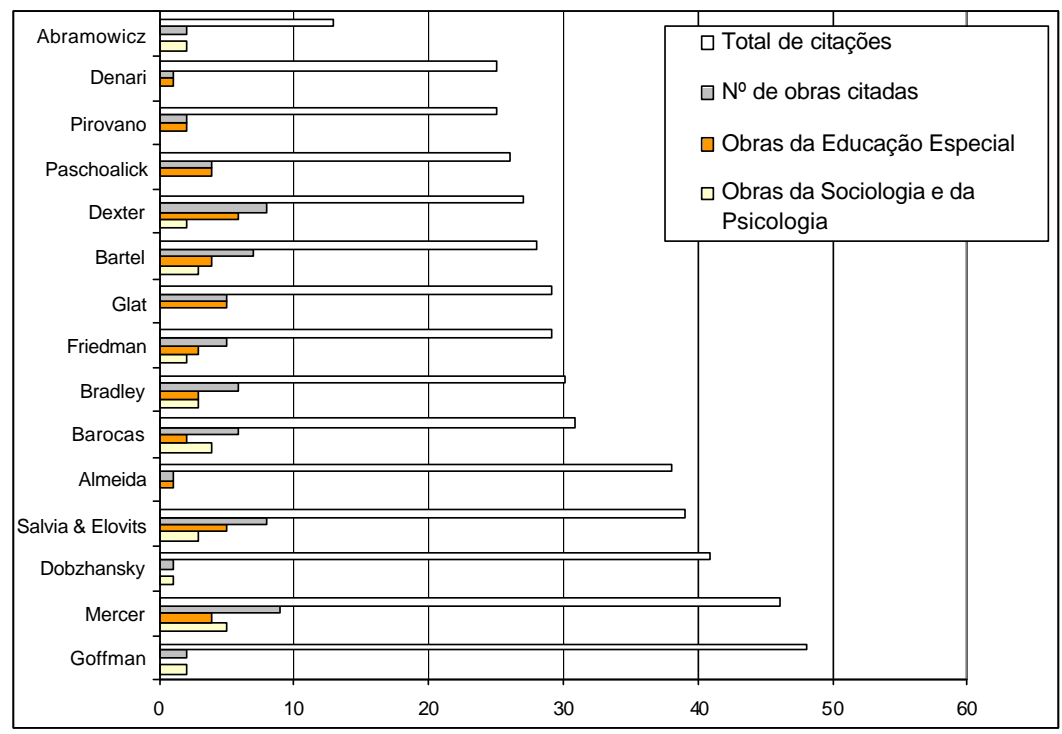

Figura 3 - Principais referencias de Sadao Omote.

O referido gráfico indica que Goffman e Mercer são as duas referências mais utilizadas por Omoteao longo de seus textos em periódicos. A mbos partem de uma conceituação social do desvio eda defi ciência, fato que por si só justifica o embasamento nestes autores. Todavia, Dobzhansky, cujas obras inter-rel acionam os elementos biológicos e culturais presentes na formação do gênero humano, materializado na assertiva de que o homem "é natu ral mentecultural e cultural mente biológico" (apud OM OTE, 2006a, p.253) aparece como a terceira referência mais citada por Omote, ou seja, a ênfase no social não o coloca em sobreposição ao biológico. 
Cabe ainda destacar Salvia, Elovits e Dexter como adeptos ao modelo de construção social da deficiência, os quais aparecem constantemente citados nos artigos de Omote, e os diversos autores que trabal ham mais especificamente com a questão da Educação Especial, principalmente aqueles que investigaram o processo de formação e desenvolvimento das classes especiais, como Almeida, Pirovano, Glat, Paschoalick, Denari e A bramowicz. Além destes, Omote se vale por diversas vezes deautores queestudaram mi nuciosamente o tema atratividade física facial, quais sejam: Barocas, Bartel, Bradley e Friedman. Por fim, convém ressal tar queao longo de seus 41 artigos Omotecita 53 diferentes trabal hos de sua autoria, compreendendo seus próprios artigos, capítulos de livro, livros, sua dissertação de mestrado e tese de doutorado. Estes 53 diferentes trabal hos são citados 223 vezes ao longo de toda sua produção em periódicos, sendo que os cinco mais citados são: Omote 1991b (15 vezes); 1991c (14 vezes); 1999b (12 vezes); $1994 a$ (12 vezes); 1995a, (11 vezes), queem conjunto somam $28 \%$ do total decitações nos artigos publicados por Omote atéo ano de2008. Estes dados são representados no gráfico quesegue (Figura 4):

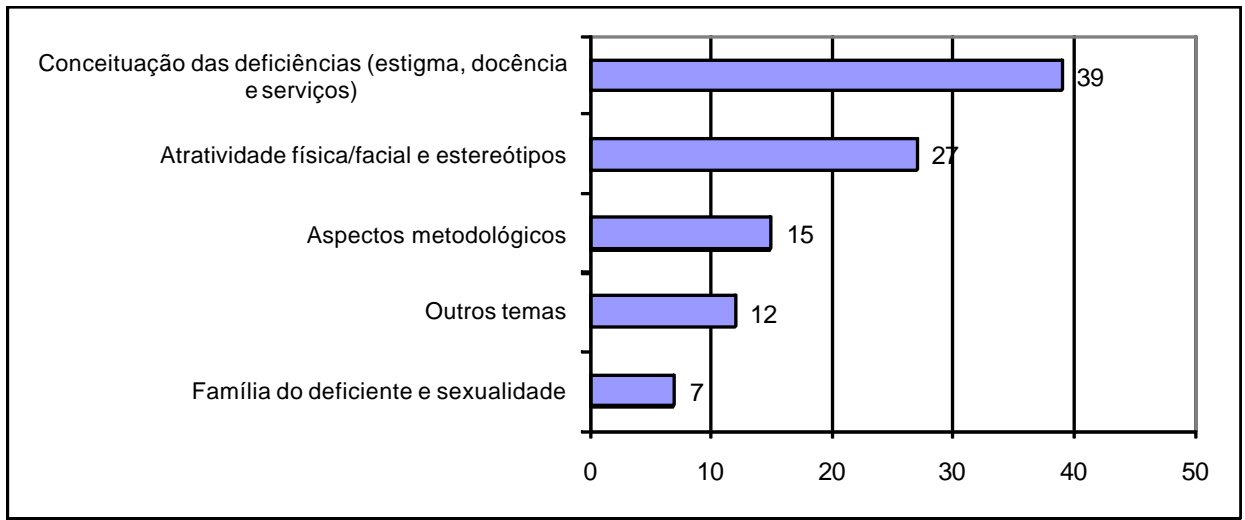

Figura 4 - Obras de autoria de Omote por ele citadas.

Portanto, percebemos que não há uma grande prevalência no processo de autocitação realizado por Omote em apenas um de seus textos. A consequência lógica deste processo é que os artigos mais vel hos recebam maiores números de citações, por isso, os dois textos considerados por nós como os mais importantes em sua trajetória acadêmica, a citar, "Inclusão ea questão das diferenças na educação" (OMOTE, 2006a), e, "E stigma no tempo da inclu são" (OM OTE, 2004b), não aparecem entre os trabal hos mais citados por Omote, mesmo porquea curva descendenteno número de produções do referido autor conjuntamente a relativa contemporaneidade destes artigos impedem quase que pela raiz a constituição de um amplo campo de referências sobre estas obras. 


\section{Conclusões}

Historicizar a obra de algum autor traz inequivocamente consigo uma interpretação acerca destas obras. A ssim, nosso texto deveser compreendido como uma tentativa deesclarecimentos das principais idéias produzidas em periódicos por Sadao Omote através de uma síntese que busca congregar os capitais elementos apontados pelo referido autor.

Isto posto, não há como deixar deressal tar que vários el ementos não menos importantes foram deixados de lado em nossas anál ises, fato que se justifica pela impossibilidadeem abarcarmos a total idade de um vasto conteúdo em apenas um único texto. Em vista disso, nosso foco estevea todo o momento direcionado sobre as formas como Omote se apropria das inter-rel ações existentes entrea diferença e a normal idade, a construção social/ biológica das deficiências, as classes especiais e a classe regular, a formação generalista e a específica, pois consideramos estas questões como engendradoras do pano de fundo ao entendimento do complexo fenômeno da inclusão e da arquitetura do próprio campo da Educação Especial .

Dito isto, esperamos que este texto possa, deal guma forma, contribuir para o entendimento de uma pequena total idade das obras de Sadao Omote. Claro está que a consecução deste objetivo se apresenta como uma tarefa árdua e tal vez não alcançável devido à limitação epistemológica dos autores queaqui expõea referida historiografia, mas, aguardamos esperançosos que, seo objetivo principal não for plenamente atingido, ao menos estetexto suscite discussões e gere apontamentos para se pensar nos principais conceitos e concepções derivadas sobre e pela Educação Especial enquanto campo acadêmico-científico, além do fato de efetivamente termos sido fiéis as idéias, opiniões e pressupostos expressos pelo referido autor, cuja materialidadeapenas poderá ser estabelecida por ele próprio.

\section{REFERÊNCIAS}

GOFFM AN, E. Estigma: notas sobrea manipulação da identidadedeteriorada. 3ed. Rio de Janeiro: Zahar, 1980.

LÊNIN, V, I. O bras escolhidas: Vladimir Ilich Lênin. São Paulo: A lfa - Ômega, 1979.

MARX, K. O Capital: crítica da economia política. São Paulo: Nova Cultural, 1996. v.1.

OM OTE, S. Inclusão e a questão das diferenças na educação. Perspectiva, Florianópolis, v. 24, p. 251-272, 2006a. 
OM OTE, S. et. al. M edidas da dinâmica respiratória em crianças de quatro a dez anos. PróFono, v. 18, p. 313-322, 2006b.

. A construção de uma escala de atitudes sociais em relação à inclusão: notas preliminares. Revista Brasileira de Educação Especial , M arília, v. 11, n. 1, p. 33-47, $2005 a$.

ARAÚJO, R. C. T.; OMOTE, S. A tribuição de gravidade à deficiência física em função da extensão do acometimento e do contexto escolar. Revista Brasileira de Educação Especial, Marília, v. 11, n. 2, p. 241-254, 2005b.

Revisão por pares na Revista Brasileira de Educação Especial. R evista Brasileira de Educação Especial, Marília, v. 11, n. 3, p. 323-334, 2005c.

. et al. Mudança de atitudes sociais em relação à inclusão. Paidéia (Ribeirão Preto), Ribeirão Preto, v. 15, n. 32, p. 387-396, 2005d.

. et al. Versão el etrônica de questionário eo controle deerros de resposta. Estu dos de Psicologia (Natal), v. 10, p. 397-405, 2005e.

. et al. Cursos de Fisioterapia e Terapia Ocupacional da Faculdade de Filosofia e Ciências - UN ESP - R evista deE xten são eP esquisa Em E ducação eS aú de, Marília, n. 2, p. 79-88, 2004a.

. Estigma no tempo da inclusão. Revista Brasileira deE ducação Especial , Marília, v. 10, n. 3, p. 287-308, 2004b.

A Igumas tendências (ou modismos?) recentes em Educação Especial ea Revista Brasileira de Educação Especial. R evista Brasileira de Educação Especial, Marília, v. 9, n. 1, p. 25-38, 2003.

. Do Centro de Orientação Educacional ao Centro de Estudos da Educação e da Saúde: em busca de maioridadeacadêmica eadministrativa... Boletim do Coe, Marília, v. 5, p. 1-5, 2000a.

Classes especiais: comentários à margem do texto de Torezan \& Caiado. R evista Brasileira de Educação Especial, Marília, v. 6, n. 1, p. 43-64, 2000 b. $\overline{1999 a .}$ 1999b.

. Componentes da atratividade física facial. Cadernos da Ffc, v. 8, n. 1, p. 87-107,

N ormal ização, integração, inclusão. P onto de V ista, Florianópolis, v. 1, n. 1, p. 4-13,

. A tratividadefísica facial e prognóstico. Psicologia Teoria eP esquisa, Brasília, v. 13, n. 1, p. 113-117, 1997.

. Perspectivas Para Conceituação de Deficiências. Revista Brasileira deEducação Especial , Piracicaba, v. 2, n. 4, p. 127-135, 1996a. . Integração do deficientena escola. Boletim do Coe, Marília, v. 1, p. 22-27, 1996b. . et al. Profissionalização do deficiente. Bol etim do Coe, Marília, v. 1, p. 40-46, 1996c. 1, p. 1-5, 1996d. et al. A trajetória do Centro de Orientação Educacional. Boletim do Coe, Marília, v. 
OMOTE, S. A família do deficiente. Temas Em E ducação Especial, São Carlos, v. 3, p. 516-525, 1996e.

. Dificul dades eperspectivas para habilitação em Educação Especial. R evista Brasileira de Educação Especial, Piracicaba, v. 2, n. 4, p. 137-145, 1996.

. et al. Uma análiseda leitura extracurricular deal unos do 1ograu. Didática-R evista Científica da U N ESP, São Paulo, v. 31, p. 163-174, 1996g.

. A Integração do Deficiente: Um Pseudo-Problema Científico. Temas em Psicologia, Ribeirão P reto, v. 2, p. 55-62, 1995a.

OMOTE, S. et al. A Entrevista Em Educação Especial: Aspectos Metodológicos. R evista Brasileira de E ducação Especial, Piracicaba, v. 2, n. 3, p. 93-100, 1995b.

. Ensino comum/ ensino especial: formação e atuação do professor. Cadernos da Ffc, Marília, v. 4, n. 2, p. 47-52, 1995c.

. Deficiência e Não-Deficiência: Recortes do Mesmo Tecido. Revista Brasileira de Educação Especial, Piracicaba, v. 1, n. 2, p. 65-73, 1994a.

. FidedignidadeN a Percepção daA tratividadeFísica Facial. Psicologia: teoria epesquisa, Brasília, v. 10, n. 2, p. 143-154, 1994b. $\overline{1993 a .}$

. As Perspectivas de Estudo das Deficiências. V ivência, São José (SC), v. 13, p. 3-4,

. A tratividadeFísica Facial ePercepção de Deficiências. D idática, São Paulo, v. 29, n. 1, p. 115-124, 1993b.

. Estudos de atratividade física facial em Educação Especial. Temas Em Educação Especial, São Carlos, v. 2, p. 273-282, 1993c.

. Relações afetivo-sexuais e o portador de deficiência. Temas Em E ducação Especial, São Carlos, v. 2, p. 381-387, 1993d.

. Reconhecimento de Estereótipos A Respeito de Pessoas Deficientes. D idática, São Paulo, v. 26, n. 1, p. 139-147, 1991a.

. Avaliação da Atratividade Física Facial: Delineamento de Um Procedimento. Psicologia: teoria e pesquisa, Brasília, v. 7, n. 3, p. 285-294, 1991b.

. Efeitos da A tratividade Física Facial de Crianças Sobre A Percepção de Outras Qualidades Delas. Psicologia: teoria e pesquisa, Brasília, v. 7, n. 3, p. 295-302, 1991c.

. A parência e Competência Em Educação Especial. T emas em E ducação Especial, São Carlos, v. 1, p. 11-26, 1990a.

OMOTE, S. etal. EntrevistaEm Educação Especial: A N atureza dosProblemas Investigados. Temas em E ducação Especial, São Carlos, v. 1, p. 67-80, 1990b.

. A Estigmatização de Deficientes e Os Serviços Especializados. V ivência, São José (SC), v. 5, p. 14-15, 1989.

. Alguns Resultados deEstudos de Estereótipos A Respeito de Pessoas Deficientes. Vivência, São José(SC), v. 4, p. 2-6, 1988. 
PICCOLO, G.M.; MOSCARDINI, S.F.; COSTA, V.B.

OMOTE, S. Estereótipos A Respeito de Pessoas Deficientes. Didática, São Paulo, v. 22, p. 167-180, 1986.

. Efeitos deUm Rótulo Verbal EstigmatizanteSobreA Percepção deEmoções. Revista

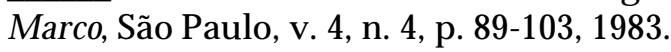

A spectos Sócio-Familiares da Deficiência Mental. R evista M arco, São Paulo, v. 1, n. 1, p. 99-113, 1979.

Recebido: 17/ 08/2009

A provado: 12/ 02/2010 